\title{
The future of clinical leadership: evidence for physician leadership and the educational pathway for new leaders
}

\author{
Amanda Goodall, ${ }^{1}$ James K Stoller ${ }^{2}$
}

'Department of Management, Cass Business School, London, UK

${ }^{2}$ Education Institute, Cleveland Clinic, Cleveland, Ohio, USA

\section{Correspondence to}

Dr Amanda Goodall, Department of Management, Cass Business School, London, UK;

Amanda.Goodall.1@city.ac.uk

Received 1 April 2017

Revised 2 May 2017

Accepted 10 May 2017

Published Online First

25 December 2017
Check for updates

To cite: Goodall A, Stoller JK. BMJ Leader 2017:1:8-11.

\section{ABSTRACT}

Until recently, the title 'physician leader' was rarely heard particularly in the UK. But that is changing. Doctors are being drawn into leadership and management more systematically. New educational opportunities are being tailored to the specific needs of doctors. The change towards physician leadership is being driven by research showing that leaders who are experts in the core business, such as doctors, are associated with improved organisational performance. This article summarises that evidence and then reviews what we have learnt about how best to train future physician leaders.

\section{INTRODUCTION}

Until recently, the title 'physician leader' was rarely heard. Naturally, this was not the case in those institutions like the Cleveland Clinic and Mayo Clinic which have been physician led from the beginning. But in the UK's National Health Service (NHS), and among many US healthcare organisations, the chief executive officer (CEO) was, and still is, more likely to be a non-clinically trained professional manager instead of a doctor. Indeed, the term 'physician leader' was viewed as almost politically incorrect. It was deemed as insulting to senior executives who were business managers, nurses or other allied professionals; and in a Darth Vader-esque narrative, physicians who assumed administrative leadership roles were considered to have gone to 'the dark side'.

But something has changed. The web is full of articles, conference announcements and educational opportunities for doctors going into leadership. The research evidence, while still sparse, is growing. To precisely attribute the actions of institutional heads to the performance outcomes of their organisations is extremely difficult. Sadly, in social science, unlike in medicine, it is not possible to randomly assign a physician leader to a hospital. But despite the many intervening variables muddying the water, patterns are emerging. The rationale for physician leadership is growing.

\section{THE CASE FOR PHYSICIAN LEADERSHIP}

In a recent article, Sarto and Veronesi review the case for 'clinical leadership and hospital performance'. ${ }^{1}$ The authors assess physician leadership at the level of CEO, clinical director and participants on hospital governing boards and quality committees. The performance measures include financial and resource management, quality of care and hospital social performance, which is a multidimensional construct that captures the relationship between hospital expenditure and benefits to local communities. The review findings, based on 18 studies, support the case for physician leadership.

The Theory of Expert Leadership (TEL) is another line of evidence that supports physician leadership. ${ }^{2}$ The theory suggests that a leader should have deep knowledge of the core business of the organisation that he or she is to lead. This line of research began by identifying simple patterns. For example, in healthcare, it was observed that the top 100 hospitals in the USA were statistically more likely to be led by physicians instead of non-medically trained managers. Specifically, among US News and World Report ranked hospitals in 2009, leadership by a physician CEO (vs a non-physician manager) was strongly associated with top quartile performance; quality scores were approximately $25 \%$ higher. ${ }^{3}$ In other settings, but this time using longitudinal data with many confounding variables, expert leaders have been shown to be associated with improved organisational performance-these include presidents and department heads in research universities, ${ }^{45}$ Formula 1 heads $^{6}$ and basketball coaches. ${ }^{7}$ It is also clear that expert leaders are not merely people who dabbled in the core business activity for a short time and then switched to management. Academics in administrative positions in universities who gave up their own research activities early in their career, have been shown to be associated with universities that performed the least well over a 10 -year period. ${ }^{8}$ Similarly, the physicians in the top-100 US News and World Report ranking mostly had long practice careers and many were also highly cited researchers.

How expert leaders exert this organisational effect has been the subject of more recent research. In a study that includes random samples of 35000 US and UK workers matched with their employers, the influence on job satisfaction of an employee's immediate boss is examined. Expert bosses are strongly associated with high levels of employee job satisfaction; indeed, boss competence is more important than pay. ${ }^{9}$ Furthermore, and in a healthcare setting, the leadership qualities of physician supervisors have also been found to influence clinician job satisfaction and well-being. ${ }^{10}$ These findings have important implications for the selection and training of physician leaders and provide new insights into organisational factors that affect physician well-being and overall productivity. Job satisfaction rates are known to be important for individual and organisational performance. ${ }^{11-14}$ 
In new research that examines faculty in universities, we again find that employees report higher levels of job satisfaction and also lower intentions to quit when they are led by core business experts (heads of departments who are distinguished researchers). ${ }^{15}$ In the same study, the possible channels of influence between an expert manager and an employee are examined. A number of positive factors are revealed: they include better feedback, allow more autonomy, greater consultation, understand the nature of the work, raise levels of morale in the workplace and greater attractiveness of the workplace to outsiders. Arguably a physician CEO may appear more credible to clinical followers both inside and outside the organisation. If an outstanding psychiatrist is the CEO of a major psychiatric hospital, this is likely to signal to new hires that the boss understands the nature of the job, and, therefore, that employees may expect a sympathetic work environment.

Beyond these observations that inform the Theory of Expert Leadership, a further rationale for training physicians to lead (and, as a corollary of leadership, to follow) is that traditional medical training crafts doctors as 'heroic lone healers' who may be 'collaboratively challenged.' This notion was articulated as early as 1976 by Marvin Weisbord who noted that "Science-based professional work differs markedly from product-based work. Health professionals learn rigorous scientific discipline as the 'content' of their training. ${ }^{16}$ The 'process' inculcates a value for autonomous decision making, personal achievement, and the importance of improving their own performance rather than that of any institution." Revamping cultures of training physicians again requires adept leadership by physicians.

A major attribute of these senior leaders is their sense of organisational altruism, a commitment to 'give back' and to assume roles as 'servant leaders' who are in service of the organisation's needs over their own. This commitment to altruism distinguishes senior leaders' impressions from more junior aspirants to leadership roles. Physician leaders who have successfully evolved into leadership roles in healthcare organisations can model their leadership behaviours and reframe their junior colleagues' impressions about effective leadership competencies-altruism, emotional intelligence, teamwork, effective communication and adeptness at situational leadership (in which the correct leadership style is deployed for the correct circumstance). In such a world, the 'command and control' leadership style that it seems has dominated traditional academic medicine begins to look different as both the 'hidden' and explicit curricula of medical leadership training.

\section{EDUCATING FUTURE PHYSICIAN LEADERS}

Thankfully, there seems to be an increasing appetite among physicians to develop their leadership skills and to assume leadership roles. But a paradox continues to pervade healthcare. On the one hand, interdisciplinary teamwork is critically important to realise the patient outcomes that all doctors care about deeply—our patients' survival, their improved well-being and an enhanced and optimal patient experience. Furthermore, in the context of the 'triple aim' to provide high-quality care that includes high patient satisfaction, patients' experience of their healthcare ${ }^{17}$ is strongly related to their perception of teamwork among their caregivers. ${ }^{18}$

On the other side of this paradox, despite the primacy of teamwork in healthcare, forces are at play that conspire against teamwork among physicians. ${ }^{19-21}$ Specifically, healthcare organisations, and in particular hospitals, are classically siloed and doctors have been traditionally organised in 'tribal' ways around their specialty and pedigree. Organisational constructs like traditional departments of medicine and surgery, which are organised around common specialtieswhile logical in their origins-subtly discourage collaboration across specialties. Consider the perennial squabble about 'fleas' and 'blades' which, on the one hand, can be dismissed as harmless banter but can also be construed as articulating 'tribalism'. Another siloed structure is the separated leadership of major units in healthcare organisations, like the hospital versus the medical school versus the faculty practice plan, which can also conspire against optimal teamwork.

Against this background, there is a critical need to reframe both the structures within healthcare and the processes by which physicians, in particular, are selected and trained. Thankfully, through mindful leadership to date, change in these processes is currently under way; for example, there is increased emphasis on human and interpersonal skills on the Medical College Achievement Test for medical school admission. Also, many medical school curricula and cultures are newly emphasising teamwork and collaboration. Yet, more pervasive change is needed.

Medical education and training should ideally be led by physicians. Major change initiatives like enhancing teamwork and collaboration among physicians, breaking down traditional silos in healthcare organisations and achieving the triple aim requires expert, hard-won leadership skills—often the product of formal curricula, mentorship and coaching by role models and by experiential learning in progressive leadership roles. So, several questions arise that are the subject of this perspective piece. Specifically: What are the leadership competencies that are needed? How should physician leadership best be taught? And how do we know if it is working?

\section{ETHICS COMPETENCIES FOR LEADERSHIP}

The rationale for committing to develop physician leaders is simply that leadership competencies matter and differ markedly from the clinical and scientific competencies on which physicians train to practice medicine or do research. The time and attention that most clinicians give to learning medicine during their training eclipses any attention that they can give to learning these leadership competencies. ${ }^{22} 23$ Thus, learning opportunities must be made available at other times. Also, evidence shows that leadership competencies, while not usually included in medical school or Graduate Medical Education (GME) curricula, can be learnt. ${ }^{24}$ For example, Boyatzis has shown that, as assessed by a standardised $360^{\circ}$ evaluation instrument, both self-awareness and management as well as social awareness and relationship management can be sustainably enhanced for up to 7 years following training on mindfulness. ${ }^{25}$ Furthermore, the weight of evidence and leadership opinion suggests that although some people have a greater natural proclivity to lead, leadership can be developed. ${ }^{26}$

ethis How then should leadership be developed? Three components comprise an ideal leadership development strategy: a curriculum of leadership competencies; offering developmental relationships, often through supportive coaching and mentoring and offering progressive and challenging leadership opportunities. ${ }^{27}$ Rabin at the Center for Creative Leadership has estimated the relative contributions of each of these elements to leaders' success; $10 \%$ is ascribed to a didactic curriculum, $20 \%$ to supportive relationships and $70 \%$ to experiential leadership opportunities. $^{28}$ 
Box 1 Features of an ideal leadership development programme

- An influential champion, the higher placed, the better (ideally chief executive officer).

- Perception that leadership is needed throughout the organisation, not only by a select few (leadership capacity is everywhere).

- The development programme must be tied to a current business imperative (eg, globalisation, growth, etc).

- Programmes must be integrated as a process in an overarching strategy, not as standalone activities.

- Location off-site is preferable.

- Dedicated facilities (eg, Crotonville) demonstrate the organisation's commitment to the process.

- Patience by organisational leadership. The dividends may take a long time to be realised.

Note: After Day and Halpin ${ }^{31}$

ethics Ample attention has been given to leadership competencies in healthcare and many proposed models have emerged. ${ }^{23}$ For example, the National Center for Healthcare Leadership model bundles 26 individual competencies into three rubrics: transformation, execution and people. ${ }^{29}$ At the Cleveland Clinic, the model used in designing its leadership curriculum is organised around 5 pillars, including emotional intelligence, which subsumes 18 competencies within 4 quadrants: self-awareness, self-management, social awareness and relationship management. ${ }^{30}$

Based on a systematic review of best-in-class leadership development programmes, Day and Halpin ${ }^{31}$ have articulated the features of an ideal lea ethis dership development programme (box 1). Indeed, although only a minority of healthcare organisations are offering leadership development programmes intramurally, ${ }^{32}$ many of those which $\mathrm{do}^{33-39}$ have incorporated the proposed design elements. These include medical societies (eg, American Thoracic Society, United States Canadian Academy of Pathology, American College of Chest Physicians, American Association for Physician Leadership), medical schools and healthcare organisations (eg, Cleveland Clinic, Mayo Clinic, Virginia Mason, McLeod Health, Hartford HealthCare, Drexel University College of Medicine, Aurora Healthcare, Emory University's Woodruff Health Sciences Center, etc) and business schools-often in affiliation with healthcare organisations (eg, Harvard Business School, The Wharton School of the University of Pennsylvania, Weatherhead School of Management of CaseWestern Reserve University and London's Cass Business School of City, University of London).

With all the money and attention that is focused on leadership development, it is important to ask what effect this training is having on physicians and their healthcare systems.

A UK study by Cambridge researcher Jaason Geerts has reviewed the literature on leadership development for doctors applying the Medical Education Research Study Quality Instrument, a validated assessment tool. Only 20 studies met the criteria, which suggests a need for more and better research. Conclusions from the review suggest that video-taped simulations with peer and expert feedback can lead to improvement in observable leadership behaviour, and action learning projects that are included in the leadership curriculum can be highly effective in demonstrating outcomes at the organisational and clinical (benefit to patients) levels. These are particularly effective when supported by 360 -degree feedback, coaching and mentoring. The best results, the study suggests, come from outcomes-based interventions. Thus, the desired postprogramme outcomes are identified at the kickoff-for the individual, the organisation and for each clinical level-and then the programme and the corresponding developmental activities are designed to reflect the desired outcomes. ${ }^{40}$

A second systematic review of 45 studies by Frich and colleagues found that only six (7.5\%) assessed system-level impact (which included quality of care process measures, promotion to leadership of course participants, improved clinical quality metrics in specific diseases (eg, diabetes, asthma, breast cancer), patient satisfaction and implementation of business plans developed during a leadership development course). A subsequent study followed 272 physician leadership course participants over a decade post-course and reported that $43 \%$ were promoted to a leadership position over that time. ${ }^{41}$

Notwithstanding these few assessments, important gaps in understanding persist. Do graduates of physician leadership programmes effect favourable change in their organisations? Are such leadership development programmes cost-effective, that is, does the financial impact of changes that are ascribable to the course offset the cost of offering the training (which includes the opportunity costs of taking physicians 'off line')? What is the optimal method to deliver a physician leadership development curriculum? Recognising that such training should likely begin early in medical training, what is the ideal 'spiral curriculum'? ${ }^{42}{ }^{43}$ How should the didactic curriculum be best integrated with mentoring and coaching of emerging leaders and with a programme of progressive, experiential leadership to optimise developing a leadership pipeline?

The imperative to develop leaders in healthcare who can address the challenges of the triple aim mandates answers to these questions, and the acuity of the need suggests that the 'plane must be built while we are flying it.' All aboard!

Amanda H Goodall, PhD, is Senior Lecturer in Management and Co-Director of the Executive Masters in Medical Leadership at Cass Business School, City, University of London. Amanda. Goodall.1@city.ac.uk

James K Stoller, MD, MS is a pulmonary/critical care physician who serves as Chairman of the Education Institute at Cleveland Clinic and Professor of Medicine at the Cleveland Clinic Lerner College of Medicine. STOLLEJ@ccf.org

Summary box

- Challenges in healthcare (eg, cost, access, quality) demand great leadership.

- Physician leadership has been associated with top quality ranking hospitals.

- Yet, physicians are not usually trained in leadership competencies and traditional selection and training cultivates individualism.

- Leadership development programmes are signature features of successful organisations and are being embraced by frontrunner healthcare organisations. 
Correction notice This paper has been amended since it was published Online First. Owing to a scripting error, some of the publisher names in the references were replaced with 'BMJ Publishing Group'. This only affected the full text version, not the PDF. We have since corrected these errors and the correct publishers have been inserted into the references.

Contributors AG and JS contributed equally to this work.

Competing interests None declared.

Provenance and peer review Commissioned; externally peer reviewed.

(c) Article author(s) (or their employer(s) unless otherwise stated in the text of the article) [year]. All rights reserved. No commercial use is permitted unless otherwise expressly granted.

\section{REFERENCES}

1 Sarto F, Veronesi G. Clinical leadership and hospital performance: assessing the evidence base. BMC Health Serv Res 2016;16:169.

2 Goodall AH. A theory of expert leadership (TEL) in psychiatry. Australas Psychiatry 2016:24:231-4

3 Goodall AH. Physician-leaders and hospital performance: is there an association? Soc Sci Med 2011:73:535-9.

4 Goodall AH. Socrates in the boardroom: why research universities should be led by top scholars. Princeton and Oxford: Princeton University Press, 2009b.

5 Goodall AH, McDowell JM, Singell LD. Do economics departments improve after they appoint a top scholar as chairperson? Kyklos. Forthcoming 2017.

6 Goodall AH, Pogrebna G. Expert leaders in a fast-moving environment. Leadership Quarterly 2015;26:123-42.

7 Goodall AH, Kahn LM, Oswald AJ. Why do leaders matter? A study of expert knowledge in a superstar setting. J Econ Behav Organ 2011;77:265-84.

8 Goodall AH. Highly cited leaders and the performance of research universities. Research Policy 2009a;38:1079-92.

9 Artz B, Goodall AH, Oswald AJ. Boss competence and worker well-being. Industrial and Labor Relations Review 2016.

10 Shanafelt TD, Gorringe G, Menaker R, et al. Impact of organizational leadership on physician burnout and satisfaction. Mayo Clin Proc 2015;90:432-40.

11 Patterson M, Warr P, West M. Organizational climate and company productivity: The role of employee affect and employee level. J Occup Organ Psychol 2004;77:193-216.

12 Oswald AJ, Proto E, Sgroi D. Happiness and productivity. Journal of Labor Economics 2014):33:789-822

13 Keller RT, Julian SD, Kedia BL. A multinational study of work climate, job satisfaction and the productivity of r\&d teas. IEEE Transactions on Engineering Management 1996;43:48-55.

14 Edmans A. Does the stock market fully value intangibles? Employee satisfaction and equity prices. J Financ Econ 2011;101:621-40.

15 Bäker A, Goodall AH. Job satisfaction and expert leaders. Working Paper 2017.

16 Weisbord MR. Why organization development hasn't worked (so far) in medical centers. Health Care Manage Rev 1976;1:17-28.

17 Institute for Healthcare Improvement. www.ihi.org/engage/initiatives/tripleaim/ pages/default.aspx. Accessed January 4, 2017

18 Wheeler D, Teamwork SJK. Teambuilding and leadership in respiratory and health care. Can J Resp Ther 2011;47.1:6-11.

19 Stoller JK. Can physicians collaborate? A review of organizational development in healthcare. OD Practitioner 2004;36:19-24.

20 Lee TH. Turning doctors into leaders. https://hbr.org/2010/04/turning-doctors-intoleaders (accessed 3 Jan 2017)
21 Weisbord M. Why hasn't organization development worked (so far) in medical centers . Healthcare Management Review 1976.

22 Stoller JK. Developing physician-leaders: a call to action. J Gen Intern Med 2009:24:876-8.

23 Stoller JK. Developing physician-leaders: need and rationale. J Health Admin Ed 2009;25:307-28

24 Boyatzis R. Emotional and social intelligence competencies. In: Ashkansky NM, Coope $\mathrm{CL}$, eds. Research Companion to Emotion in Organizations, Edward Elgar Publishing Inc., 2008.

25 Kirkpatrick S, Locke E. Leadership: Do traits matter? In: Steers RM, Porter LW, Bigley GA, eds. Motivation and leadership at work. 6th ed. New York: McGraw-Hill, 1996:186-99.

$26 \mathrm{McC}$ all M, Morrison LM. The lessons of experience: how successful executives develop on the Job. New York: Free Press, 1988.

27 Rabin R; Blended learning for leadership: The CCL approach. Center for Creative Leadership. www.ccl.org/wp-content/uploads/2015/04/BlendedLearningLeadership. pdf

28 Rabin R. Blended learning for leadership: the CCL approach. Center for Creative Leadership. www.ccl.org/wp-content/uploads/2015/04/BlendedLearningLeadership. pdf (accessed 21 Jan 2017).

29 Calhoun JG, Dollett L, Sinioris ME, et al. Development of an interprofessional competency model for healthcare leadership. J Healthc Manag 2008:53:375-91.

30 Goleman D, Boyatzis R, McKee A. Primal leadership: the hidden drive of great performance. Harv Bus Rev 2001:42-51.

31 Day DV, Halpin SM. Leadership development: A review of industry best practices. Review on corporate training. Technical Report. http://www.au.af.mil/au/ awc/awcgate/army/tr1111.pdf.

32 Davidson PL, Azziz R, Morrison J, et al. Identifying and developing leadership competencies in health research organizations: a pilot study. J Health Adm Educ 2012;29:135-54.

33 Stoller JK, Berkowitz E, Bailin PL. Physician management and leadership education at the Cleveland Clinic Foundation: program impact and experience over 14 years. J Med Pract Manage 2007:22:237-42.

34 Christensen T, Stoller JK. Physician leadership development at Cleveland Clinic: a brief review. Australas Psychiatry 2016;24:235-9.

35 Schwartz RW, Pogge C. Physician leadership: essential skills in a changing environment. Am J Surg 2000;180:187-92.

36 Scott HM, Tangalos EG, Blomberg RA, et al. Survey of physician leadership and management education. Mayo Clin Proc 1997;72:659-62.

37 Schwartz RW, Pogge CR, Gillis SA, et al. Programs for the development of physician leaders: a curricular process in its infancy. Acad Med 2000;75:133-40.

38 Dannels SA, Yamagata H, McDade SA, et al. Evaluating a leadership program: a comparative, longitudinal study to assess the impact of the Executive Leadership in Academic Medicine (ELAM) Program for women. Acad Med 2008:83:488-95.

39 Korschun HW, Redding D, Teal GL, et al. Realizing the vision of leadership development in an academic health center: the Woodruff Leadership Academy. Acad Med 2007;82:264-71.

40 Geerts J. A systematic literature review on leadership development for doctors. Working Paper 2017.

41 Frich JC, Brewster AL, Cherlin EJ, et al. Leadership development programs for physicians: a systematic review. J Gen Intern Med 2015;30:656-74.

42 Nowacki A, Barss C, Christensen T, et al. Emotional intelligence and physician leadership potential: a longitudinal study supporting a link. JHAE 2016;33:23-41.

43 Stoller JK, Taylor CA, Farver CF. Emotional intelligence competencies provide a developmental curriculum for medical training. Med Teach 2013;35:243-7. 